\title{
Feasibility of an experiential community garden and nutrition programme for youth living in public housing
}

\author{
Karissa Grier ${ }^{1}$, Jennie L Hill ${ }^{1}$, Felicia Reese ${ }^{1}$, Constance Covington $^{2}$, \\ Franchennette Bennette ${ }^{2}$, Lorien MacAuley ${ }^{3}$ and Jamie Zoellner ${ }^{1, *}$ \\ 'Department of Human Nutrition, Foods, and Exercise, Virginia Polytechnic Institute and State University, Virginia \\ Tech, Integrated Life Sciences Building 23, Room 1034 (0913), 1981 Kraft Drive, Blacksburg, VA 24061, USA: \\ ${ }^{2}$ Danville Redevelopment \& Housing Authority, Danville, VA, USA: ${ }^{3}$ Department of Agricultural, Leadership, and \\ Community Education, Virginia Tech, Blacksburg, VA, USA
}

Submitted 20 June 2014: Final revision received 26 October 2014: Accepted 15 December 2014: First published online 23 February 2015

\begin{abstract}
Objective: Few published community garden studies have focused on low socioeconomic youth living in public housing or used a community-based participatory research approach in conjunction with youth-focused community garden programmes. The objective of the present study was to evaluate the feasibility (i.e. demand, acceptability, implementation and limited-effectiveness testing) of a 10-week experiential theory-based gardening and nutrition education programme targeting youth living in public housing.

Design: In this mixed-methods feasibility study, demand and acceptability were measured using a combination of pre- and post-programme surveys and interviews. Implementation was measured via field notes and attendance. Limited-effectiveness was measured quantitatively using a pre-post design and repeated-measures ANOVA tests.

Setting: Two public housing sites in the Dan River Region of south central Virginia, USA.

Subjects: Forty-three youth (primarily African American), twenty-five parents and two site leaders.

Results: The positive demand and acceptability findings indicate the high potential of the programme to be used and be suitable for the youth, parents and site leaders. Field notes revealed numerous implementation facilitators and barriers. Youth weekly attendance averaged 4.6 of 10 sessions. Significant improvements $(P<0.05)$ were found for some (e.g. fruit and vegetable asking self-efficacy, overall gardening knowledge, knowledge of MyPlate recommendations), but not all limited-effectiveness measures (e.g. willingness to try fruits and vegetables, fruit and vegetable eating self-efficacy).

Conclusions: This community-based participatory research study demonstrates numerous factors that supported and threatened the feasibility of a gardening and nutrition programme targeting youth in public housing. Lessons learned are being used to adapt and strengthen the programme for future efforts targeting fruit and vegetable behaviours.
\end{abstract}

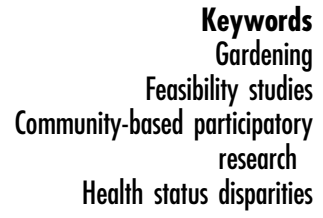

Keywords

lity studies research Health status disparities
A diet high in fruits and vegetables $(\mathrm{F} \& \mathrm{~V})$ can protect against numerous diseases (e.g. diabetes, heart disease, cancer $^{(1)}$. Inadequate consumption of F\&V in the USA is well documented and is especially problematic among youth $^{(2)}$. Of further concern, youth of lower socioeconomic status (SES) consume inadequate amounts of F\&V compared with their higher-SES counterparts ${ }^{(3)}$. Inadequate $\mathrm{F} \& \mathrm{~V}$ consumption is largely due to the lack of accessibility and affordability, problems often seen in health-disparate and low-income areas, especially among blacks $^{(3)}$. Due to the low intake of F\&V in youth from lowSES backgrounds, there is a need to promote F\&V intake among this population.

One potential intervention approach to address insufficient F\&V intake among youth from disadvantaged regions, and the focus of the present research, is the use of community gardens (CG). A CG is a shared gardening space and can provide food, physical and social benefits 
to participants ${ }^{(4)}$. CG have been implemented in various settings including schools, after-school programmes and places of worship in the USA and abroad $^{(5-7)}$. CG have been used to increase access to $\mathrm{F} \& \mathrm{~V}$ and have demonstrated effectiveness in increasing F\&V self-efficacy, preference and other theoretical constructs related to behaviour change ${ }^{(8,9)}$. However, few published CG studies have focused on youth from low-SES backgrounds ${ }^{(8-10)}$.

Community-based participatory research (CBPR) is defined as a collaborative research effort between researchers and community members to address the community's needs ${ }^{(11)}$. The collaborative nature of CBPR may assist in reaching vulnerable populations and help to reduce health disparities within disadvantaged communities $^{(12-14)}$. Despite these strengths, and as recently recognized in a seminal review, CBPR approaches have not been utilized in conjunction with CG efforts for youth $^{(8)}$. The CG programme reported here was planned and implemented as part of a community-academic partnership, highlighting a key component of CBPR in which the community partners are involved in all phases of the research process, including problem assessment ${ }^{(13)}$.

Originating in 2009, the Dan River Partnership for a Healthy Community (DRPHC) is a community-academic partnership operating under CBPR principles. The DRPHC's mission is 'to foster community partnerships to combat obesity in the Dan River Region through healthy lifestyle initiatives ${ }^{,(15)}$. Detailed elsewhere, community stakeholders developed six causal models for obesity and identified CG as a priority initiative to address the nutrition causal model $^{(16)}$. To advance this identified priority, the DRPHC formed a nutrition subcommittee which included site leaders of housing authorities, religious leaders and congregation members with gardening or farming experience, extension agents with agricultural and nutrition expertise, and Virginia Tech researchers from the Department of Human Nutrition, Foods, and Exercise.

Given the interest in CG, the nutrition subcommittee initiated a series of regional garden forums and pilot projects targeting CG in the region ${ }^{(15)}$. The annual forums serve as an opportunity for community members to contribute new ideas for progression of the CG initiative and as a platform for dissemination of results to community members. The first pilot project was a mixed-methods study conducted in the summer of 2010. Results indicated that perceptions and interest of community members for participating in a CG were high and that children in the region would be interested in participating in a CG programme and eating food grown from a garden ${ }^{(17)}$.

Subsequently, a mixed-methods case study was conducted in 2011 to explore the potential public health impact of six CG that had been recently established in the Dan River Region ${ }^{(18)}$. These CG included two churchbased, two school-based and two community-based gardens. These organizations were successful in securing local funding to support the initiative and start-up costs of their gardens ${ }^{(19)}$. Interviews and focus groups revealed that garden leaders and participants were enthusiastic about impacts of the CG, expressed interest in continuing to garden and requested educational programming to accompany the CG initiative. Yet the degree to which lowincome persons and youth were being involved in the CG efforts was unclear. Additionally, although there was general consensus and enthusiasm for engaging youth in gardening combined with nutrition education, the coalition partners were unsure of the potential of such a programme to succeed. These results and concerns were discussed at the second annual CG forum and attendees expressed desire to implement a youth-based CG programme in the region.

Based on this progress, the next goal was to engage youth in regional CG efforts. At this point, the DRPHC had successfully secured funding to establish CG programmes in partnership with the regional public housing authority. Two sites within the housing authority that had active on-site youth programming were identified as partners for these efforts. Leaders from these two sites were already partners in the larger DRPHC and had been involved in the grant development process. Therefore, the objective of the summer 2012 project was to explore the feasibility of an experiential theory-based CG and nutrition education programme for youth living in public housing. Using Bowen and colleagues' recommendations for designing a feasibility study, the present research reports on four focus areas, including demand, acceptability, implementation and limited-effectiveness testing ${ }^{(20)}$.

\section{Research methods}

The present mixed-methods study was guided by recommendations for designing a feasibility study ${ }^{(20)}$. Given the early stage of development of the youth CG programme, four focus areas were used to evaluate feasibility, including demand, acceptability, implementation and limitedeffectiveness testing. The 10-week theory-based experiential education programme was implemented at the youth centres of two housing authorities between May and August of 2012. The study was conducted according to the guidelines laid down in the Declaration of Helsinki and all procedures involving human subjects/patients were approved by the Institutional Review Board at Virginia Tech. Parents provided written informed consent and youth provided oral assent prior to study activities.

\section{Study area and participants}

The Dan River Region is situated in south central Virginia and north central North Carolina. All counties in this region meet the medically underserved area/population classification, with high indices of poverty, low educational attainment and health disparities ${ }^{(21)}$. There are no regional data specific to the nutrition, health or well-being 
of youth. However, low-SES, rural and African-American populations in Virginia consistently experience higher mortality rates and poorer health status across a variety of outcomes when compared with higher-SES, urban and non-black Virginians ${ }^{(22)}$. Two public housing sites that were active members of the DRPHC and predominantly served families were targeted by this project. Internal census data from the two housing authority sites indicate that $97 \%$ of housing residents were black, $85 \%$ of the households were headed by single women, and more than 125 households had two or more children under the age of 14 years. Of these children, $45 \%$ were male. Additionally, the income limit for public housing is <\$US 17500 annually per family.

\section{Recruitment and participants}

The partnering adult site leaders were familiar with youth and families at each location and had roles to engage youth in directed activities and distribute recruitment materials and flyers; in some instances, visiting families in their homes to provide programme information. Researchers also spent time at each site to inform potential participants about the programme. Using a communityfriendly approach, eligibility criteria were broad. The only inclusion criteria were youth to be 5-17 years of age and both the youth and parent had to reside full-time at the housing authority.

Of the forty-three enrolled youth, the majority ( $n$ 42; 97.7\%) were African American. The mean age was 8.7 years and included twenty ( $46.5 \%)$ males and twentythree $(53.5 \%)$ females. BMI $Z$-scores indicated that the majority of youth were overweight $(34.1 \%)$ or obese (18.2\%). When compared with the internal housing authority census data, the enrolled youth were representative in terms of race and gender.

\section{Programme development and delivery}

The CG educational material was adapted from the Junior Master Gardener curriculum ${ }^{(23)}$, including changes to incorporate nutrition-focused lessons, to align more closely with the Social Cognitive Theory ${ }^{(24)}$ and to address cultural relevance for the targeted youth (Table 1). One example of a modification for cultural relevance is the use of a popular line dance and song in place of the standard song for teaching proper hand washing during the Food Safety lesson. There are two versions of the Junior Master Gardener curriculum (i.e. level one for grades 3-5 and level two for grades $6-8$ ). The level one curriculum was chosen for this pilot as it was intended for the younger age range. Lessons were chosen based on learning objectives, including providing experiential learning experiences in the garden and perceived ease of delivery by the researchers. To supplement the Junior Master Gardener curriculum with nutritionfocused content, publicly available information from the US Department of Agriculture's MyPlate website ${ }^{(25)}$ was used. The Social Cognitive Theory focuses on how behaviours can be acquired and maintained through reciprocal determinism $^{(26)}$ (the interrelation between a person's behaviour and his/her environment) and incorporates various constructs to promote behaviour changes such as knowledge, self-efficacy, outcome expectations, goal setting and reinforcement. This theory is commonly used for understanding and changing health behaviours ${ }^{(27)}$, is useful when working with youth to influence health behaviours ${ }^{(28)}$ and may significantly promote improved dietary habits ${ }^{(29)}$.

Each site had access to a garden. One site had established a garden in the previous year and had six to eight raised beds enclosed in a locked fenced area. The second site had not previously had a garden and had limited space to create one. Thus, three hanging pots and four large gardening containers were used. Researchers delivered the programme once weekly at both sites, providing approximately $60 \mathrm{~min}$ of interactive gardening or nutrition education and $30 \mathrm{~min}$ of hands-on gardening. Weeks 1-4 focused on gardening and weeks 5-9 focused on nutrition education. Week 10 featured a review of key concepts and a graduation ceremony. To increase participants' engagement throughout the programme, two reward systems were created, one to promote meeting weekly goals (i.e. paper cut-outs of growing plant) and one to increase programme participation (i.e. star stickers for active participation). The programme was offered during regular operating hours at the youth centres at each site. The programme was intended for the youth enrolled; however, no restrictions were set for other residents. Thus, unenrolled youth and siblings and parents of enrolled children would often attend the lessons.

In addition to the housing authorities' site leaders' role in problem identification (e.g. identified CG as a regional priority initiative ${ }^{(16,17)}$, collaboration in the nutrition subcommittee and grant funding, and recruitment of youth), they also assisted in the planning, initiation and maintenance of the gardens. Site leaders were provided with and trained to use a standard scale and log book to measure and record produce harvested from the garden. Site leaders were also informally instructed in basic garden maintenance techniques to be applied with the youth in during the days when the academic team was not present to deliver the programme. For example, the site leaders supervised the watering, weeding and harvest of the gardens during the programme. Due to timeline constraints with the grant and planning/training logistics, the site leaders were not directly involved in adaptation or delivery of the curriculum. However, the opportunity to more fully involve the site leaders in curriculum delivery was seen as a future goal, and site leaders were encouraged to and often attended the sessions as a training opportunity.

\section{Feasibility measures}

As illustrated in Table 2, measurement focused on four areas of feasibility including demand, acceptability, implementation and limited-effectiveness testing ${ }^{(20)}$. 
Table 1 Curriculum overview corresponding to Social Cognitive Theory (SCT) constructs; gardening and nutrition education programme for youth living in public housing, Dan River Region of south-central Virginia, USA, 2012

\begin{tabular}{|c|c|c|}
\hline Weeks and lesson topics & Learning objectives & SCT constructs \\
\hline Week 1: Basic gardening, Part 1 & $\begin{array}{l}\text { - To accurately identify plant parts and parts that are eaten } \\
\text { - To understand the purpose of plants and what they need to live and grow } \\
\text { - To learn and commit to garden rules and duties } \\
\text { - To introduce weekly goals for eating F\&V }\end{array}$ & $\begin{array}{l}\text { Self-efficacy } \\
\text { Environment and situation } \\
\text { Reciprocal determinism } \\
\text { Reinforcement } \\
\text { Goal setting }\end{array}$ \\
\hline Week 2: Basic gardening, Part 2 & $\begin{array}{l}\text { - To be knowledgeable in plant spacing and planting in appropriate temperature zones } \\
\text { - To gain confidence in ability to select locations to grow gardens } \\
\text { - To gain confidence in ability to plant crops during appropriate seasons }\end{array}$ & $\begin{array}{l}\text { Reciprocal determinism } \\
\text { Reinforcement } \\
\text { Goal setting } \\
\text { Self-efficacy } \\
\text { Environment and situation }\end{array}$ \\
\hline Week 3: Gardening techniques & $\begin{array}{l}\text { - To understand processes of water cycle and how it relates to plant needs } \\
\text { - To be knowledgeable about the plant life cycle } \\
\text { - To gain confidence in ability to garden and harvest F\&V }\end{array}$ & $\begin{array}{l}\text { Self-efficacy } \\
\text { Outcome expectations } \\
\text { Reinforcement } \\
\text { Goal setting } \\
\text { Behavioural capability } \\
\text { Reciprocal determinism }\end{array}$ \\
\hline Week 4: Garden maintenance & $\begin{array}{l}\text { - To be knowledgeable and skilled in organic gardening practices and } \\
\text { its importance for sustainability } \\
\text { - To gain confidence in ability to solve problems in the garden }\end{array}$ & $\begin{array}{l}\text { Self-efficacy } \\
\text { Emotional coping responses } \\
\text { Outcome expectations } \\
\text { Reciprocal determinism } \\
\text { Goal setting } \\
\text { Reinforcement }\end{array}$ \\
\hline Week 5: Basic food nutrition, Part 1 & $\begin{array}{l}\text { - To be knowledgeable and confident about basic nutrition, MyPlate, and functions and } \\
\text { sources of macro- and micronutrients } \\
\text { - To understand the health benefits of eating F\&V } \\
\text { - To gain confidence in ability to try new F\&V and eat more F\&V }\end{array}$ & $\begin{array}{l}\text { Behavioural capability } \\
\text { Reciprocal determinism } \\
\text { Goal setting } \\
\text { Self-efficacy } \\
\text { Reinforcement } \\
\text { Outcome expectations }\end{array}$ \\
\hline Week 6: Basic food nutrition, Part 2 & $\begin{array}{l}\text { - To understand the importance of portion sizes } \\
\text { - To attain positive expectations about eating healthy snacks } \\
\text { - To gain confidence in ability to choose healthy options for snacks } \\
\text { - To increase willingness to try healthy options for snacks }\end{array}$ & $\begin{array}{l}\text { Outcome expectations } \\
\text { Goal setting } \\
\text { Self-efficacy } \\
\text { Behavioural capability } \\
\text { Observational learning } \\
\text { Reciprocal determinism } \\
\text { Reinforcement }\end{array}$ \\
\hline Week 7: Safe practices & $\begin{array}{l}\text { - To understand the importance of safe food practices in preventing illness or injury } \\
\text { - To gain confidence in ability to perform safe practices when preparing food }\end{array}$ & $\begin{array}{l}\text { Self-efficacy } \\
\text { Behavioural capability } \\
\text { Outcome expectations } \\
\text { Environment and situation } \\
\text { Goal setting } \\
\text { Reinforcement }\end{array}$ \\
\hline Week 8: Healthful eating & $\begin{array}{l}\text { - To increase willingness to try new F\&V } \\
\text { - To gain positive expectations of consuming F\&V } \\
\text { - To gain confidence in ability to prepare healthy foods and eat them regularly } \\
\text { - To improve capabilities of preparing healthy kid-friendly recipes at home }\end{array}$ & $\begin{array}{l}\text { Self-efficacy } \\
\text { Goal setting } \\
\text { Reciprocal determinism } \\
\text { Observational learning } \\
\text { Behavioural capability } \\
\text { Outcome expectations }\end{array}$ \\
\hline Week 9: In-class tasting & $\begin{array}{l}\text { - To increase willingness to try new F\&V } \\
\text { - To gain confidence in ability to try new F\&V } \\
\text { - To gain positive expectations of consuming F\&V }\end{array}$ & $\begin{array}{l}\text { Reciprocal determinism } \\
\text { Self-efficacy } \\
\text { Outcome expectations } \\
\text { Behavioural capability } \\
\text { Goal setting } \\
\text { Reinforcement }\end{array}$ \\
\hline Week 10: Recap and close & $\begin{array}{l}\text { - To increase willingness to try new F\&V } \\
\text { - To gain confidence in ability to eat F\&V and garden } \\
\text { - To be knowledgeable about basic nutrition and gardening }\end{array}$ & $\begin{array}{l}\text { Self-efficacy } \\
\text { Reciprocal determinism } \\
\text { Outcome expectations } \\
\text { Reinforcement }\end{array}$ \\
\hline
\end{tabular}

$\mathrm{F} \& \mathrm{~V}$, fruits and vegetables. 
Demand and acceptability

Demand examines the extent that a new programme will be used by the participants. Acceptability reflects the degree to which a programme is viewed as satisfactory by the participants. These constructs were measured in the youth, parents and site leaders. For the youth, postprogramme interviews were conducted, including eight open-ended questions pertaining to enjoyment of the programme, perceived benefits of participating in the programme and suggestions for programme improvement. For the parents, twenty-nine pre-programme quantitative questions were asked, including beliefs about maintaining a garden, the expected benefits of working in a garden, confidence in participating in a garden and general interest in gardening. At post-programme, parents were asked to self-complete eight open-ended questions related to demand and acceptability. For the two site leaders, postprogramme interviews included nine open-ended questions pertaining to recruitment experience, data collection perception, demands of continuing to provide a garden and use the curriculum, and perceived benefits or acceptability of the programme.

\section{Implementation}

Implementation is the degree to which a programme is delivered as intended. Implementation measures were completed by the three Virginia Tech researchers who delivered the programme to assess feasibility of implementation. Evaluations were completed after programme delivery, each week, at each site. Consensus among the three evaluators was achieved through discussion of the session. Three questions reflected the extent to which the lesson was delivered as intended and the barriers and facilitators to delivery. Additionally, field notes were used to document opportunities and challenges for curriculum implementation. Finally, weekly attendance records were used to measure the proportion of youth participating.

\section{Limited-effectiveness testing}

Limited-effectiveness refers to the potential of a programme to be successful while tested in a limited way; in this case, low statistical power. Limited-effectiveness was tested using measures that were assessed at baseline and follow-up. All data collectors were trained according to a standardized protocol. Interview-administered surveys included previously validated measures (i.e. willingness to try $F \& V^{(30)}$, self-efficacy for eating $F \& V^{(31)}$, self-efficacy for asking for $F \& V^{(32)}$ ), as well as measures developed for the purposes of the study (i.e. expectations for eating F\&V, self-efficacy for gardening, gardening knowledge and nutrition knowledge). These measures were primarily chosen based on core constructs from the Social Cognitive Theory ${ }^{(24)}$, the theoretical framework guiding the study. Based on previous literature, yet recognizing limitations with adequate power, we hypothesized trends of improvements for each of these measures. Additionally, height and weight were measured 
using a portable stadiometer and Tanita body fat analyser (model TBF-310GS), respectively.

\section{Data analysis}

All data were managed and analysed by the researchers who delivered the programme. Qualitative data from postprogramme interviews were transcribed verbatim ${ }^{(33)}$. Two researchers then generated a list of codes from the initial review of the transcripts. Subsequently, three researchers independently coded the transcripts and met to resolve disagreements and build consensus through discussion of the codes. Similarly, field notes were reviewed and evaluated for recurring themes regarding barriers, facilitators and other observations. Data entry and analysis for the quantitative measures were conducted in the statistical software package IBM SPSS Statistics for Windows, version 20.0. Descriptive statistics were used to summarize variables and Cronbach's $\alpha$ was used to assess the reliability of each scale at baseline, with the exception of the knowledge-based scales. Since the Cronbach's $\alpha$ for outcome expectations for eating F\&V was below the level of acceptability, results are not reported. For all the limited-effectiveness measures that are detailed in Table 4, overall effects were tested with repeated-measures ANOVA. An intent-to-treat analysis using the last observation carried forward method (i.e. for noncompleters, baseline value is substituted for postintervention value (assumes a zero change)) was used, along with analysis using complete cases only ${ }^{(34)}$. Findings did not vary by approach; therefore, intent-to-treat results are presented. A critical value of 0.05 was used for significance testing. Using a standard equation for reporting effect sizes on a single-group, pre-post study design (i.e. (average pre-test score - average post-test score)/average $\mathrm{SD})$, estimated effect sizes are also reported.

\section{Results}

\section{Demand and acceptability}

Of the forty-three enrolled youth, twenty-five (58.1\%) completed the post-programme interviews. As detailed in Table 3, the majority of youth expressed positive impressions with the most liked components including food sampling, games and gardening experiences. The most common suggestions for improving recruitment and programme engagement were increased distribution of printed materials and door-to-door solicitation.

Twenty-five parents completed the pre-programme questionnaire. Expected benefits of working in a garden averaged 5.36 (SD 0.90; 7-point scale where $1=$ 'extremely unlikely', $7=$ 'extremely likely'). Beliefs about maintaining a garden averaged 5.25 (SD 1.34; 7-point scale where $1=$ 'extremely unenjoyable', $7=$ 'extremely enjoyable'). Confidence in participating in a garden averaged 3.65 (SD $1 \cdot 12$; 5-point scale where $1=$ 'not at all confident', $5=$ 'very confident'). Interest in gardening averaged $7 \cdot 85$
(SD 1.92; 10-point scale where $1=$ 'strongly disagree', $10=$ 'strongly agree'). Fifteen parents also completed the post-programme questionnaire. Most (87\%) confirmed that the time of day that the programme was offered was convenient. Some (53\%) expressed that their children demonstrated new asking behaviour in requesting fruits, vegetables or new preparation methods for vegetables. When asked about their interest in allowing their children to participate in a future gardening programme, the majority (93\%) indicated that they noticed an increase in their child's confidence in gardening and would allow their child to participate in a CG programme again.

Both site leaders expressed several benefits of the programme. Both described better cohesion and positive interactions among the youth who participated in the programme. They also observed an increase in the children's willingness to try F\&V that were served as part of the summer feeding programme. Lastly, both also expressed intentions to continue to have a garden and excitement at the possibility of having the programme delivered again in the following summer.

\section{Implementation}

The extent to which lessons were delivered as intended was measured on a 5-point scale (i.e. $1=$ 'not at all', $5=$ 'completely') and averaged 4.60 (SD 0.88). Field notes revealed various facilitators and barriers to implementation. The most commonly recorded barrier was noise and distractions from the children. This resulted in the need to stop delivery and focus on classroom management, which detracted from the lessons. Conversely, the most frequently noted facilitator was the involvement of site leaders. While site leaders did not deliver content, their established role as a respected authority figure was essential to classroom management. Another noteworthy challenge was the presence of parents during the lessons. Parents would often answer questions before allowing the children the opportunity to answer. Also, parents would vocalize their disdain for certain F\&V which was perceived by the researchers as a possible hindrance to participants' willingness to try F\&V. Similar issues were noted in the garden. Children were often distracted, requiring time to manage crowd control. During times when a crop was ready for harvest and an impromptu tasting opportunity was available, parents and other onlookers would express negative comments about sampling food directly from the garden. Again, site leaders' relationship with the youth was beneficial during food sampling activities as they role modelled the behaviour of trying unfamiliar foods. Youth weekly attendance averaged 4.80 (SD 0.63 ) and 4.40 (SD 1.07) out of 10 sessions, at the site with raised beds and site with containers, respectively.

\section{Limited-effectiveness}

Of the forty-three youth enrolled, thirty-two (74.4\%) completed follow-up assessments. Compared with those 
Table 3 Emergent codes and quotes reflecting youths' experiences and impression of the gardening and nutrition programme for youth living in public housing, Dan River Region of south-central Virginia, USA, 2012

\begin{tabular}{|c|c|c|c|}
\hline Interview question & Code & $\begin{array}{l}\text { Number of } \\
\text { mentions }\end{array}$ & Sample quote \\
\hline What did you like most about the programme? & $\begin{array}{l}\text { Trying food } \\
\text { Gardening experience } \\
\text { Curriculum content } \\
\text { Programme in general } \\
\text { Playing games and activities }\end{array}$ & $\begin{array}{r}10 \\
8 \\
4 \\
3 \\
2\end{array}$ & $\begin{array}{l}\text { 'Trying vegetables' } \\
\text { 'Learning how to plant and about F\&V' } \\
\text { 'It fun and we get to learn about new stuff and eat new stuff' } \\
\text { 'I liked the programme questions', } \\
\text { 'Games and trying different foods' }\end{array}$ \\
\hline What did you like least about the programme? & $\begin{array}{l}\text { Did not dislike anything } \\
\text { Trying food }\end{array}$ & $\begin{array}{l}7 \\
2\end{array}$ & $\begin{array}{l}\text { 'Liked everything' } \\
\text { 'Trying spinach' }\end{array}$ \\
\hline $\begin{array}{l}\text { What ideas do you have for us to make the programme } \\
\text { more fun or exciting in the future? }\end{array}$ & $\begin{array}{l}\text { Increase games } \\
\text { Increase food sampling } \\
\text { Increase variety of plants }\end{array}$ & $\begin{array}{l}8 \\
3 \\
3\end{array}$ & $\begin{array}{l}\text { 'More games' } \\
\text { 'Have more samples' } \\
\text { 'New seeds' }\end{array}$ \\
\hline How has the programme helped you with gardening? & $\begin{array}{l}\text { Increased knowledge of gardening } \\
\text { Increased interest in gardening } \\
\text { Increased knowledge of healthy eating }\end{array}$ & $\begin{array}{l}9 \\
5 \\
3\end{array}$ & $\begin{array}{l}\text { 'Taught [me] how to keep bugs/pests away' } \\
\text { 'Now I know I want to garden because it seems exciting and } \\
\text { it's tasty' } \\
\text { 'It's helped me learn. I can stop eating so much junk food and } \\
\text { start eating fruit' }\end{array}$ \\
\hline $\begin{array}{l}\text { How has the programme helped you with nutrition and } \\
\text { eating F\&V? }\end{array}$ & $\begin{array}{l}\text { Learned about nutrition in general } \\
\text { Increased F\&V intake } \\
\text { Tried new foods } \\
\text { Increased knowledge of healthy eating }\end{array}$ & $\begin{array}{l}6 \\
4 \\
4 \\
3\end{array}$ & $\begin{array}{l}\text { 'It did; gave me more knowledge' } \\
\text { 'It's helped me eat F\&V' } \\
\text { 'Tried new vegetables' } \\
\text { 'It has made me know about different F\&V that I didn't think } \\
\text { about before' }\end{array}$ \\
\hline $\begin{array}{l}\text { If any, what are some new fruits and vegetables you've } \\
\text { tried since starting the programme? }\end{array}$ & $\begin{array}{l}\text { New fruit } \\
\text { New vegetables } \\
\text { New F\&V }\end{array}$ & $\begin{array}{l}8 \\
8 \\
6\end{array}$ & $\begin{array}{l}\text { 'Strawberries, grapes' } \\
\text { 'Spinach, tomatoes, and squash' } \\
\text { 'String beans, corn, peas, oranges, apples, grapes' }\end{array}$ \\
\hline $\begin{array}{l}\text { Do you think you will continue to set goals to eat the } \\
\text { recommended amount of } F \& V \text { after the programme ends? }\end{array}$ & $\begin{array}{l}\text { Yes } \\
\text { Not sure }\end{array}$ & $\begin{array}{r}21 \\
3\end{array}$ & $\begin{array}{l}\text { 'Yes' } \\
\text { 'Maybe' }\end{array}$ \\
\hline \multirow[t]{2}{*}{$\begin{array}{l}\text { How do you think we can get more kids from your } \\
\text { neighbourhood to come to the programme? }\end{array}$} & $\begin{array}{l}\text { Distribute printed material } \\
\text { Have large recruitment event } \\
\text { Door-to-door solicitation }\end{array}$ & $\begin{array}{l}7 \\
4 \\
4\end{array}$ & $\begin{array}{l}\text { 'Give more flyers' } \\
\text { 'Come outside with a microphone and talk' } \\
\text { 'Knock on their door and ask their mom if they can come if } \\
\text { they are not in it. Let them know they can be in the } \\
\text { programme if they live nearby' }\end{array}$ \\
\hline & $\begin{array}{l}\text { Encourage word of mouth through } \\
\text { children }\end{array}$ & 2 & 'We can ask friends' \\
\hline
\end{tabular}

$\mathrm{F} \& \mathrm{~V}$, fruits and vegetables. 
Table 4 Limited efficacy measures, using last observation carried forward ( $n$ 43), before and after participation in the gardening and nutrition programme for youth living in public housing, Dan River Region of south-central Virginia, USA, 2012

\begin{tabular}{|c|c|c|c|c|c|c|c|c|}
\hline \multirow[b]{2}{*}{ Variable } & \multirow[b]{2}{*}{ Cronbach's a } & \multirow[b]{2}{*}{ Number of Items } & \multicolumn{2}{|c|}{ Pre-test score } & \multicolumn{2}{|c|}{ Post-test score } & \multirow[b]{2}{*}{ Effect size* } & \multirow[b]{2}{*}{$P$} \\
\hline & & & Mean & SD & Mean & SD & & \\
\hline Willingness to try F\&V† & 0.86 & 26 & 1.43 & 0.42 & 1.47 & 0.42 & $0 \cdot 10$ & 0.310 \\
\hline Self-efficacy for eating $F \& V \ddagger$ & 0.75 & 13 & 1.61 & 0.35 & 1.68 & 0.31 & 0.21 & 0.119 \\
\hline Self-efficacy for asking for F\&V & 0.72 & 8 & 1.70 & 0.37 & 1.83 & 0.29 & 0.39 & 0.013 \\
\hline Self-efficacy for gardening $\ddagger$ & 0.47 & 6 & 1.75 & 0.31 & 1.81 & 0.28 & $0 \cdot 20$ & 0.058 \\
\hline Gardening knowledge§ & $\mathrm{N} / \mathrm{A}$ & 25 & 14.53 & 3.45 & $15 \cdot 74$ & 3.90 & 0.33 & 0.01 \\
\hline Plant parts§ & $\mathrm{N} / \mathrm{A}$ & 6 & $2 \cdot 16$ & 1.36 & 2.56 & 1.30 & 0.30 & 0.045 \\
\hline Plant needs§ & $\mathrm{N} / \mathrm{A}$ & 6 & $4 \cdot 37$ & 0.98 & 4.37 & 1.45 & 0.00 & 1.00 \\
\hline Plant life cycle§ & N/A & 9 & 5.53 & 1.75 & 5.35 & 1.77 & -0.10 & 0.489 \\
\hline Garden maintenance§ & $\mathrm{N} / \mathrm{A}$ & 4 & 2.05 & 1.07 & $2 \cdot 14$ & 1.04 & 0.09 & 0.400 \\
\hline Nutrition knowledge§ & $\mathrm{N} / \mathrm{A}$ & 23 & 12.65 & 2.29 & $12 \cdot 86$ & 1.97 & $0 \cdot 10$ & 0.583 \\
\hline MyPlate§ & $\mathrm{N} / \mathrm{A}$ & 10 & 5.65 & 1.54 & $6 \cdot 26$ & 1.47 & 0.40 & 0.049 \\
\hline Macronutrients§ & $\mathrm{N} / \mathrm{A}$ & 9 & 3.70 & 1.24 & 3.65 & 1.54 & -0.04 & 0.849 \\
\hline Food safety§ & $\mathrm{N} / \mathrm{A}$ & 4 & $3 \cdot 30$ & 0.64 & 2.95 & 0.21 & -0.82 & 0.001 \\
\hline
\end{tabular}

F\&V, fruits and vegetables; N/A, not applicable.

Repeated-measures ANOVA were used to test effects.

*(Average pre-test score - average post-test score)/average sD.

†Responses were on a 3-point scale: $0=$ 'not willing'; 1 = 'may be willing'; 2 = 'willing'.

$\ddagger$ Responses were on a 3-point scale; $0=$ 'no'; 1 = 'maybe'; 2 = 'yes'

$\S$ Responses coded as $1=$ correct; $0=$ incorrect.

retained, youth who were lost to follow-up did not vary significantly by race, age or gender. As detailed in Table 4, significant improvements were found for self-efficacy for asking for $\mathrm{F} \& \mathrm{~V}$, overall gardening knowledge, knowledge of plant parts (sub-category of gardening knowledge) and knowledge of MyPlate categories. Estimated effect sizes for these outcomes were moderate, ranging from 0.30 to $0 \cdot 40$. However, the knowledge of food safety decreased significantly at follow-up. There were no significant effects on willingness to try F\&V, self-efficacy for eating F\&V, selfefficacy for gardening, other knowledge sub-categories or overall nutrition knowledge. Nevertheless, the majority of non-significant effects trended in a positive direction (six of eight variables).

\section{Discussion}

The present feasibility study explored the demand and acceptability, implementation and limited-effectiveness of a theory-based experiential gardening and nutrition programme through collaborative CBPR efforts. The study addresses recommendations for utilizing CBPR in CG efforts $^{(8)}$ and builds on community-identified research priorities of the DRPHC ${ }^{(15,17,18)}$. Given the early stages of the youth-based CG programme in the region, it was apparent that a feasibility project would be most appropriate $^{(20)}$. Bowen and colleagues ${ }^{(20)}$ describe three feasibility questions that represent the phases of intervention development: 'can it work?', 'does it work?' and 'will it work?'. The 'can it work?' question was the driving basis to understand the programme and to define additional research priorities. The quantitative and qualitative feasibility findings provide important insights on understanding if CG can work in public housing authority systems within the Dan River Region.

To our knowledge, the present study is the first one published to jointly implement gardens within low-income housing settings and deliver a gardening and nutrition programme specifically targeting low-income youth living in public housing settings. Although there are several reviews that illustrate the effects, benefits and challenges of $\mathrm{CG}^{(8,9)}$, there is a lack of published CG feasibility studies with which to compare our study findings. Of one known study, a thesis describes the feasibility of a garden-based nutrition programme delivered to pre-school children ${ }^{(35)}$. It was concluded that delivering such a programme was feasible, based on a positive response to at least $80 \%$ of questions asked of teachers who delivered the programme; yet other measures of feasibility (e.g. implementation) were not addressed. In our study, the demand and acceptability findings indicate the high potential of the programme to be used and be suitable for the youth, parents and site leaders. The implementation findings demonstrate that the programme can be implemented by researchers with a high level of fidelity. On the contrary, the feasibility outcomes also reveal several issues that can threaten the likelihood of programme success, such as classroom management, lack of specific components geared towards the parents at the educational/experiential sessions and intermittent programme attendance. Future efforts should consider redefining and/or narrowing the age range eligibility (e.g. 8-13 years), refining programme curriculum (e.g. increase food sampling activities in each weekly module) and developing targeted recruitment and retention strategies (e.g. offer alongside the US Department of Agriculture's summer feeding programme). Due to interest among parents and their desire to participate, incorporating specific 
parent components may also improve the success of the programme outcomes.

Most youth-based CG research focuses solely on efficacy/effectiveness or outcome measures ${ }^{(36-41)}$. Outcomes from the limited-effectiveness measures in our project both refute and support other studies ${ }^{(37,38)}$. There were no differences in willingness to try $\mathrm{F} \& \mathrm{~V}$, although other studies have documented that experiential gardening with increased exposure to $\mathrm{F} \& \mathrm{~V}$ is effective in increasing children's willingness to try $F \& V^{(37,42)}$. On the contrary, we found significant improvements of F\&V selfefficacy, whereas one other study did not ${ }^{(36)}$. Similar to our knowledge findings, numerous other studies have revealed mixed results for changes in nutrition and/or gardening knowledge ${ }^{(8)}$. Taken as a whole, our study yielded relatively similar results to previous youth-based CG studies, which indicate promising, yet mixed findings across a variety of theoretical and behavioural outcomes $^{(8)}$. Importantly, our estimated effect sizes provide an indication of the number of youth who will be needed in future programming to achieve adequately power for statistical testing on behavioural outcomes. Based on our limited-effectiveness feasibility findings, areas for future direction may include a stronger study design with a control arm, a larger sample and opportunities to revise effectiveness measures (e.g. refine theory-based measures based on item statistics, add measures of F\&V intake/ behaviour, reduce the number of self-reported items, add observation items for willingness to try).

Both residential-based and school-based CG have advantages and challenges in engaging youth ${ }^{(10,43,44)}$. For the current study, the gardens were supported by the housing authority, established on site and located at the youth centres within the neighbourhoods which the housing authority operates year round to serve residents. This convenient location allowed the children to participate without concern for transportation and allowed the gardens to be maintained by site leaders. Also, the youth centres provide free on-site snacks, lunch and dinner, which provides an opportunity to incorporate fresh produce from the garden and discuss. These benefits may contribute to a higher likelihood of sustainability of the garden and the programme in the community. One potential disadvantage of using housing authorities is the variability in the presence of the youth. As mentioned previously, all youth participating in the programme lived in single female-headed households. Visitation with the second parent as well as participation in other summer activities and vacations could interfere with consistent attendance. In contrast, school-based gardens provide can also provide unique opportunities when compared with residential-based gardens, such as integration of gardening and nutrition lessons with standard curriculum. Some studies implemented in schools have demonstrated increases in willingness to try $\mathrm{F} \& \mathrm{~V}^{(38,45)}, \mathrm{F} \& \mathrm{~V}$ consumption ${ }^{(46,47)}$ and nutrition knowledge ${ }^{(38,45,47-49)}$. Notably, improvements in school-based outcomes (e.g. academic enhancement, environmental awareness and social development ${ }^{(10,43,44)}$ ) have also been achieved, although with mixed effects. One notable disadvantage to school gardens is the time period in which schools are usually closed during the summer, which prevents youth from participating in a peak growing season and poses concern for maintenance ${ }^{(44)}$.

While many programmes directed to youth focus exclusively on nutrition outcomes or school-based outcomes, there are future opportunities for simultaneously targeting school-based learning and behavioural outcomes. An effort to bridge residential-based and schoolbased gardens could enhance the attributes and reduce the challenges of each. For example, hands-on workshops and trainings could be provided through PTA (ParentTeacher Association) meetings throughout the school year. Knowledge and skills gained could allow parents, youth and other community members to be involved in the maintenance of the school garden during the summer break and in the residential garden. Additionally, workshops provide an opportunity to train faculty, staff and community members in quantitative research techniques to objectively evaluate F\&V consumption. For the present study, youth and staff were instructed on how to use a scale to measure produce harvested from the garden. However, this did not capture changes in F\&V purchase or consumption in the home. The use of additional objective measures, such as direction observation (e.g. plate waste) or other dietary assessment techniques, could provide evidence for the effectiveness of CG in improving F\&V consumption and behaviours ${ }^{(50,51)}$.

Potential limitations of the present study include the absence of a control group, small sample size, wide age range and varying level of attendance. These factors may explain some of the discrepancies with the prior literature. Other studies with larger samples have demonstrated that groups with education and experience have better outcomes when compared with a control group ${ }^{(37,38)}$. Additionally, many studies cluster youth by two or three grades ${ }^{(39-41)}$. In our study, to accommodate the goals and objectives of the housing authority, youth centres aimed at providing enjoyable and enriching activities to youth under 18 years old, youth in our programme had a much larger age range (i.e. 5-17 years). However, to promote appropriateness of lesson content and age-appropriate measures, this approach may be revised for future programming and age eligibility will be reduced to a tighter range as seen in other similarly designed studies ${ }^{(35,37,38)}$. Despite these limitations, the present study served its purpose in further establishing community-academic partnerships and providing feasibility data from which to revise, improve and expand the programme.

In its design, this current study used four of the eight focus areas set forth in the guidelines by Bowen and colleagues for designing feasibility studies ${ }^{(20)}$. Demand, acceptability, implementation and limited-effectiveness were deemed 
the most relevant given the early stages of development for this CG initiative and they allowed us to determine the potential utility of a gardening and nutrition education programme. Additional areas of focus such as adaptation, integration and expansion should be used to guide the development, implementation and evaluation of future phases. For example, adaptation examines programme performance when implemented with modifications or to a different population, whereas integration reflects the extent that a new programme can be incorporated into an existing system and expansion measures the degree to which a tested programme can be expanded to provide a new programme. In the context of the CBPR nature of this CG initiative, one of the most important future opportunities is to more fully involve the housing authority leaders in programme adaptations, curriculum delivery and data collection activities. Future efforts to secure funding should carefully consider the time and resources needed to more fully engage the housing authority leaders. Strategically promoting the capacity of the housing authorities to implement and evaluate the programme will be critical to long-term sustainability. Likewise, deliberate efforts to actively engage the older youth at the sites to assist in planning, implementation and evaluation activities should be incorporated. Expanding to include these additional areas of focus, as presented by Bowen and colleagues, will allow for future evaluation aimed at answering the 'does it work?' and 'will it work?' questions. Importantly, the results from this 2012 CG programme were disseminated back to the community in spring 2013 at the third annual CG forum. Due to positive reception of the programme from community members, site leaders, youth and parents, efforts are currently underway to improve the programme and expand it to involve more stakeholders and youth using the CBPR approach.

Given the documented lack of F\&V intake and accessibility among low-SES youth across numerous healthdisparate regions, other health and nutrition-related practitioners and researchers may apply the lessons learned in this feasibility study to investigate theory-driven attempts to target youth with CG programmes. Results and lessons learned from this feasibility study provide insights to continue exploring CG as a culturally relevant CBPR approach to address F\&V access, knowledge and health behaviours within low-income youth in the Dan River Region.

\section{Acknowledgements}

Acknowledgements: The authors recognize efforts from members of the Dan River Partnership for a Healthy Community (DRPHC) nutrition subcommittee, especially Tawanna Fountain, and the entire DRPHC coalition. They thank the graduate and undergraduate students from Virginia Tech for their assistance in data collection, including Ramine Alexander, Angie Bailey, Jessica Li,
Nicole Olive, Maggie Reinhold, Clarice Waters and Grace Wilburn. Financial support: Funding for this project was provided, in part, by the Virginia Foundation for a Healthy Youth. The Virginia Foundation for a Healthy Youth had no role in the design, analysis or writing of this article. Conflict of interest: None. Authorship: J.Z., K.G. and J.L.H. conceptualized and drafted the paper. Each author contributed to further development and revisions of the paper and approved the final submission. J.Z. and J.L.H. contributed to securing grant funding for the project and oversaw conceptualization of the study design, measurement and evaluation. Other co-authors assumed a unique role in execution of the project including: C.C. and F.B. directed participant recruitment and garden maintenance; K.G., F.R. and L.M. managed curriculum development and delivery. Ethics of buman subject participation: All materials and procedures were approved by the Institutional Review Board at Virginia Tech.

\section{References}

1. Van Duyn MA \& Pivonka E (2000) Overview of the health benefits of fruit and vegetable consumption for the dietetics professional: selected literature. J Am Diet Assoc 100, 1511-1521.

2. Kimmons J, Gillespie C, Seymour J et al. (2009) Fruit and vegetable intake among adolescents and adults in the United States: percentage meeting individualized recommendations. Medscape J Med 11, 26.

3. Hanson MD \& Chen E (2007) Socioeconomic status and health behaviors in adolescence: a review of the literature. J Behav Med 30, 263-285.

4. American Community Garden Association (n.d.) Growing Community Across the U.S. and Canada. https://community garden.org/mission/ (accessed February 2013).

5. Davis JN, Ventura EE, Cook LT et al. (2011) LA Sprouts: a gardening, nutrition, and cooking intervention for Latino youth improves diet and reduces obesity. J Am Diet Assoc 111, 1224-1230.

6. Gatto NM, Ventura EE, Cook LT et al. (2012) LA Sprouts: a garden-based nutrition intervention pilot program influences motivation and preferences for fruits and vegetables in Latino youth. $J$ Am Diet Assoc 112, 913-920.

7. Somerset S \& Markwell K (2009) Impact of a school-based food garden on attitudes and identification skills regarding vegetables and fruit: a 12 -month intervention trial. Public Health Nutr 12, 214-221.

8. Robinson-O'Brien R, Story M \& Heim S (2009) Impact of garden-based youth nutrition intervention programs: a review. J Am Diet Assoc 109, 273-280.

9. Langellotto GA \& Gupta A (2012) Gardening increases vegetable consumption in school-aged children: a metaanalytical synthesis. HortTechnology 22, 430-445.

10. Williams DR \& Dixon PS (2013) Impact of gardenbased learning on academic outcomes in schools synthesis of research between 1990 and 2010. Rev Educ Res 83, 211-235.

11. Israel BA (2005) Methods in Community-Based Participatory Research for Health. San Francisco, CA: Jossey-Bass.

12. Horowitz CR, Colson KA, Hebert PL et al. (2004) Barriers to buying healthy foods for people with diabetes: evidence of environmental disparities. Am J Public Health 94, 1549-1554. 
13. Minkler M, Blackwell AG, Thompson M et al. (2003) Community-based participatory research: implications for public health funding. Am J Public Health 93, 1210-1213.

14. O'Toole TP, Aaron KF, Chin MH et al. (2003) Communitybased participatory research: opportunities, challenges, and the need for a common language. J Gen Intern Med 18, 592-594.

15. Dan River Partnership for a Healthy Community (n.d.) Mission and Vision. http://www.drhealthycommunity.org/ about-us/mission-and-vision/ (accessed February 2013).

16. Zoellner J, Motley M, Wilkinson ME et al. (2012) Engaging the Dan River Region to reduce obesity: application of the comprehensive participatory planning and evaluation process. Fam Community Health 35, 44-56.

17. Zoellner J, Zanko A, Price B et al. (2012) Exploring community gardens in a health disparate population: findings from a mixed methods pilot study. Prog Community Health Partnersh 6, 153-165.

18. Zanko A, Hill JL, Estabrooks P et al. (2014) Evaluating community gardens in a health disparate region: a qualitative case study approach. J Hunger Environ Nutr 9, 1-33.

19. Kelder SH, Perry CL, Klepp KI et al. (1994) Longitudinal tracking of adolescent smoking, physical-activity, and food choice behaviors. Am J Public Health 84, 1121-1126.

20. Bowen DJ, Kreuter M, Spring B et al. (2009) How we design feasibility studies. Am J Prev Med 36, 452-457.

21. US Department of Health and Human Services, Health Resources and Service Administration (n.d.) Find Shortage Areas: MUA/P by State and County. http://muafind.hrsa. gov/ (accessed February 2013).

22. Virginia Department of Health, Office of Minority Health \& Public Health Policy (2008) Unequal Health Across the Commonwealth: A Snapshot. Richmond, VA: Virginia Department of Health; available at http://www.vdh.virginia. gov/omhhe/documents/health-equity-report-08.pdf

23. JMG Kids (2004) Junior Master Gardener Presents Wildlife Gardener. College Station, TX: JMG Kids.

24. Bandura A (1989) Human agency in social cognitive theory. Am Psychol 44, 1175-1184.

25. ChooseMyPlate.gov (n.d.) Home page. http://www. choosemyplate.gov/ (accessed February 2013).

26. Bandura A (1986) Social Foundations of Thought and Action: A Social Cognitive Theory. Englewood Cliffs, NJ: Prentice Hall.

27. Baranowski T, Mendlein J, Resnicow K et al. (2000) Physical activity and nutrition in children and youth: an overview of obesity prevention. Prev Med 31, Suppl. 2, S1-S10.

28. Lytle L \& Achterberg C (1995) Changing the diet of America's children: what works and why? J Nutr Educ 27, 250-260.

29. Resnicow K, Davis-Hearn M, Smith M et al. (1997) Socialcognitive predictors of fruit and vegetable intake in children. Health Psychol 16, 272-276.

30. Thomson JL, McCabe-Sellers BJ, Strickland E et al. (2010) Development and evaluation of WillTry. An instrument for measuring children's willingness to try fruits and vegetables. Appetite 54, 465-472.

31. Geller KS, Dzewaltowski DA, Rosenkranz RR et al. (2009) Measuring children's self-efficacy and proxy efficacy related to fruit and vegetable consumption. J Sch Health 79, 51-57.

32. Domel S, Thompson W, Davis H et al. (1996) Psychosocial predictors of fruit and vegetable consumption among elementary school children. Health Educ Res 11, 299-308.

33. Creswell JW (2012) Qualitative Inquiry and Research Design: Choosing Among Five Approaches. Thousand Oaks, CA: SAGE Publications.
34. DeSouza CM, Legedza AT \& Sankoh AJ (2009) An overview of practical approaches for handling missing data in clinical trials. J Biopharm Stat 19, 1055-1073.

35. Lewis TM (2009) Determining the feasibility and acceptability of a garden-based nutrition curriculum for preschoolers. PhD Thesis, University of Texas.

36. Heim S, Stang J \& Ireland M (2009) A garden pilot project enhances fruit and vegetable consumption among children. J Am Diet Assoc 109, 1220-1226.

37. Morgan PJ, Warren JM, Lubans DR et al. (2010) The impact of nutrition education with and without a school garden on knowledge, vegetable intake and preferences and quality of school life among primary-school students. Public Health Nutr 13, 1931-1940.

38. Morris J, Neustadter A \& Zidenberg-Cherr S (2001) Firstgrade gardeners more likely to taste vegetables. Calif Agric (Berkeley) 55, 43-46.

39. Parker SP, Siewe YJ \& Denney BA (2006) After-school gardening improves children's reported vegetable intake and physical activity. J Nutr Educ Behav 38, 201-202.

40. Poston SA, Shoemaker CA \& Dzewaltowski DA (2005) A comparison of a gardening and nutrition program with a standard nutrition program in an out-of-school setting. HortTechnology 15, 463-467.

41. Reynolds KD, Franklin FA, Binkley D et al. (2000) Increasing the fruit and vegetable consumption of fourthgraders: results from the high 5 project. Prev Med 30, 309-319.

42. Birch LL, McPhee L, Shoba B et al. (1987) What kind of exposure reduces children's food neophobia? Looking vs. tasting. Appetite $9,171-178$.

43. Blair D (2009) The child in the garden: an evaluative review of the benefits of school gardening. J Environ Educ $\mathbf{4 0}$, $15-38$.

44. Ozer EJ (2007) The effects of school gardens on students and schools: conceptualization and considerations for maximizing healthy development. Health Educ Behav 34, 846-863.

45. Cason KL (1999) Children are 'growing healthy' in South Carolina. J Nutr Educ 31, 235-236.

46. McAleese JD \& Rankin LL (2007) Garden-based nutrition education affects fruit and vegetable consumption in sixthgrade adolescents. J Am Diet Assoc 107, 662-665.

47. Ratcliffe MM, Merrigan KA, Rogers BL et al. (2011) The effects of school garden experiences on middle school-aged students' knowledge, attitudes, and behaviors associated with vegetable consumption. Health Promot Pract 12, $36-43$.

48. Morris JL \& Zidenberg-Cherr S (2002) Garden-enhanced nutrition curriculum improves fourth-grade school children's knowledge of nutrition and preferences for some vegetables. J Am Diet Assoc 102, 91-93.

49. Parmer SM, Salisbury-Glennon J, Shannon D et al. (2009) School gardens: an experiential learning approach for a nutrition education program to increase fruit and vegetable knowledge, preference, and consumption among secondgrade students. J Nutr Educ Behav 41, 212-217.

50. Dhingra P, Sazawal S, Menon VP et al. (2007) Validation of visual estimation of portion size consumed as a method for estimating food intake by young Indian children. $J$ Health Popul Nutr 25, 112-115.

51. Williamson DA, Allen HR, Martin PD et al. (2003) Comparison of digital photography to weighed and visual estimation of portion sizes. J Am Diet Assoc 103, 1139-1145. 